\title{
AUDIENCIAS DE CUSTÓDIA NA COMARCA DE FORTALEZA, CEARÁ: análise de dados do ano de 2016
}

\author{
Italo Farias Braga' \\ Nestor Eduardo Araruna Santiago 2 \\ Amanda Furtado Mendes 3 \\ Jessyka Mendes Dias Simões 4 \\ 衰 Lohana Giafony Freitas de Luna ${ }^{5}$
}

\section{Palavras-Chave}

audiência de custódia / prisão

preventiva / Comarca de Fortaleza

Introdução. 1. Das Audiências de Custódia. 2. Parâmetros de análise dos dados. 3. Verificação de dados. 4. Conclusão. Referências.

\footnotetext{
Mestre em Direito Constitucional no Programa de Pós-Graduação Stricto Sensu em Direito Constitucional da Universidade de Fortaleza (UNIFOR). Advogado. Bolsista FUNCAP.

${ }^{2}$ Doutor em Direito, com estágio pós-doutoral (Universidade do Minho, Portugal). Professor Titular do Programa de Pós-Graduação Stricto Sensu em Direito Constitucional e do Curso de Graduação em Direito da Universidade de Fortaleza (UNIFOR). Professor Orientador coordenador do Laboratório de Ciências Criminais (LACRIM) da UNIFOR. Advogado criminalista.

3Estudante do Curso de Graduação em Direito da Universidade de Fortaleza (UNIFOR). Pesquisadora voluntária (PAVIC) no Laboratório de Ciências Criminais (LACRIM) da UNIFOR.

${ }^{4}$ Estudante do Curso de Graduação em Direito da Universidade de Fortaleza (UNIFOR). Pesquisadora com bolsa CNPq no Laboratório de Ciências Criminais (LACRIM) da UNIFOR.

Estudante do Curso de Graduação em Direito da Universidade de Fortaleza (UNIFOR). Pesquisadora com bolsa CNPq no Laboratório de Ciências Criminais (LACRIM) da UNIFOR.
}

\section{Resumo}

A implementação das audiências de custódia a partir do Projeto Nacional Audiência de Custódia representou desafio técnico e jurídico para a concretização dos direitos previstos no Pacto de San José da Costa Rica. Este trabalho teve por objetivo analisar empiricamente a implementação das Audiências de Custódia na Comarca de Fortaleza, Estado do Ceará. Para tal, fez-se uso do relatório de dados fornecido pela Vara Única e privativa de custódia, analisando-se os dados de quantidades de autuações, tipos de decisão proferidas e dispersão dos dados verificados, calculados com base no coeficiente de dispersão de Pearson. Tomaram-se por base apenas os dados referentes ao ano de 2016. Verificou-se que, de um total de 7.433 autuações, apenas 5.948 resultaram em alguma das decisões possíveis, ou seja, decretação de preventiva, concessão de liberdade provisória ou relaxamento do flagrante. Das decisões totais, em $52,25 \%$ dos casos houve decretação de preventiva; em 36,31\% houve concessão de liberdade provisória e somente em $0,46 \%$ houve relaxamento de prisão. Notou-se ainda que os dados oscilam mês a mês, de modo que o único dado estável é o de decretação de preventivas, enquanto o dado de relaxamentos de prisão varia relativamente aos demais em maior intensidade, o que sugere uma subnotificação de ilegalidades nas custódias realizadas na comarca no período verificado. 


\title{
CUSTODY HEARING IN THE COMARCA DE FORTALEZA, CEARÁ: data analysis for the year 2016
}

\author{
Italo Farias Braga \\ Nestor Eduardo Araruna Santiago \\ Amanda Furtado Mendes \\ Jessyka Mendes Dias Simões \\ 重 Lohana Giafony Freitas de Luna
}

\section{Keywords}

custody hearing / empirical study / Fortaleza Jurisdiction

\section{Resumo}

The implementation of the custody hearings from the National Custody Hearing Project represents a technical and legal challenge for the realization of the rights prescribed by the San Jose of Costa Rica Pact. This search intends to do an empirical analysis of the implementation of the legal institutions of Fortaleza's jurisdiction. It was intended to verify the 17 a criminal judges' information about how many prisons were made and the kind of decisions that were taken, calculated based on Pearson's dispersion coefficient. The data base was taken from 2016. It was verified that out of a total of 7,433 assessments, $80 \%$ resulted in a preventive order (granting of provisional release or flagrant relaxation). In $52.25 \%$ of the current cases there were preventive decrees, in $36.31 \%$ of the cases, provisional freedoms were conceded and only $0.46 \%$ resulted in relaxation of illegalities. It was also noted that the data oscillates month by month in such way that the only stable data is based on preventive decree, while the data of prison relaxation varies with more intensity. This suggests a low indices of notification of illegalities in the audiences of the region during the period. 


\section{INTRODUÇÃO}

O projeto nacional Audiência de Custódia, capitaneado pelo Conselho Nacional de Justiça (CNJ), configurou marco importante no controle de convencionalidade entre as normas do processo penal brasileiro e a as normas previstas na Convenção Americana de Direitos Humanos (CADH) - Pacto de San José da Costa Rica - e do Pacto Internacional de Direitos Civis e Políticos (PIDCP).

Neste contexto, foi promulgada a Resolução n. 213/2015 pelo CNJ (R213), instituindo a regulamentação da audiência de custódia pelos estados ainda sem normatização sobre este tema. Além desse fim, as audiências de apresentação sofreram padronização de procedimento de acordo com as determinações internacionais.

A R213 foi criada em decorrência de debates doutrinários e de edição de diversas normas, tais quais a o Termo de Cooperação Técnica n. 7 (TCT7), que implicou em judicialização no Supremo Tribunal Federal (STF). Este se defrontou com o tema na Ação Direta de Inconstitucionalidade n. 5240 (ADI 5240) e na Ação Direta de Descumprimento de Preceito Fundamental n. 347 (ADPF 347).

As audiências de custodia foram instituídas com uma série de objetivos, como o desencarceramento, a ruptura da barreira fria do contato entre o juiz e o preso - normalmente feita no momento do interrogatório judicial -, bem como na garantia de que os direitos do custodiado sejam cumpridos, evitandose tortura, maus tratos e ferimento aos direitos humanos.

No Estado do Ceará, as audiências de custodia ingressaram mediante a Resolução $n$. 14/2015 (R 14), do Órgão Especial do Tribunal de Justiça (TJCE). Nesta, houve regulamen- tação impondo a realização das custodias e definindo a $17^{a}$ Vara Criminal de Fortaleza como a Vara Única Privativa de Custodias na Comarca de Fortaleza.

Este trabalho tem por objetivo a verificação da implementação das audiências de custódia na comarca de Fortaleza, de tal modo que se buscou a tabulação, rotulação e compreensão dos dados coletados na $17^{a}$ Vara Criminal para perceber como têm sido aplicadas estas audiências e se há a efetividade para o suprimento de seus objetivos.

Em relação à abordagem, o presente estudo, embora eminentemente quantitativo, ao verificar os dados de prisão relativos às quantidades e decisões aplicadas nas audiências de custódia na Comarca de Fortaleza, averiguou-se o caráter quali-quantitativa. Visto que se faz também análise qualitativa, ao verificar os porquês da implementação das audiências de custódia, tornando a pesquisa quali-quanti. Em relação aos procedimentos, foi realizado levantamento de dados e pesquisa bibliográfica, bem como análise documental. Quanto aos objetivos, a pesquisa é descritiva, vez que busca apresentar e verificar como são os dados na realidade. Em relação à natureza, está é básica, de modo que é feita pela ciência, sem objetivo prático pré-determinado (GERHARDT E SILVEIRA, 2009).

A metodologia está assentada na análise do relatório de dados coletados pela $17^{a}$ Vara Criminal de Fortaleza (Vara Única e Especializada em Audiências de Custódia), com a busca pelos padrões estatísticos das medidas de tendência central, representados neste trabalho pelas médias e quantidades de autuações, prisões preventivas, liberdades provisórias e relaxamentos de ilegalidades, tabulados mês a mês no ano de 2016. 
Em seguida coletou-se os padrões de discrepância entre os dados, de modo que se guardou os dados de desvio-padrão, variância e o coeficiente relativo de Pearson.

Estes dados foram tabulados com a referência temporal no período de janeiro a dezembro do ano de 2016 em seguimentos mensais e foram trabalhados pelo aplicativo Excel para a construção de tabelas e uso de calculadora automática. Para auxiliar os cálculos utilizou-se a fórmula padrão "(=média(A:B)); (=desvpad(A:B)); (=VARP(A:B))". Já o cálculo do coeficiente relativo de Person, utilizou-se a fórmula "C = (100*D/M)", onde $C$ representa o coeficiente de Pearson, D o Desvio-Padrão dos dados analisados e $\mathrm{M}$ a média dos dados analisados

Por fim, esta pesquisa foi realizada no âmbito do Projeto de Pesquisa intitulado "Quis custodiet ipsos custodes? Sobre os caminhos da audiência de custódia no Estado do Ceará", cadastrado na Plataforma de Pesquisa da Universidade de Fortaleza. Desta forma, constitui parte de um projeto maior de estudos acerca da implementação das audiências de custódia no Estado do Ceará.

Isto posto, busca-se o estudo da implantação das audiências de custódia na Comarca de Fortaleza/CE, averiguando a implementação da R213 e os efeitos da R14 do órgão especial do TJCE referente a eficácia das audiências de custódia no Estado.

Assim, no primeiro item do trabalho, indica-se a formulação legislativa das audiências de custódia, o arcabouço doutrinário e os critérios jurídicos de exigibilidade. No segundo item, fala-se dos parâmetros dos dados analisados, para que seja adequada a metodologia quantitativa às conclusões qualitativas colacionadas e no terceiro item aborda-se os dados, de modo a correlacio- nar os métodos com os resultados obtidos.

Portanto, formula-se a hipótese que há a exigibilidade das audiências de custódia, mas que a aplicação prática desta não implica diretamente nos resultados esperados com os objetivos de sua criação. Então, no caso, percebe-se a dificuldade na consecução do objetivo jurídico de extirpar a tortura da atividade policial.

\section{DAS AUDIÊNCIAS DE CUSTÓDIA}

Define-se a audiência de custódia, audiência de apresentação ou de controle de detenção, como a garantia que qualquer preso em flagrante tem de ser levado à presença da autoridade judiciária, sem demora, para que se analise a legalidade ou não da sua prisão. Trata-se de instituto utilizado em diversos países e chancelado pela Corte Interamericana de Direitos Humanos (Cortel$\mathrm{DH})$ para prevenir a tortura, os maus tratos, bem como para garantir um efetivo Estado de Direito.

Desta feita, as audiências de custódia têm regulamentação pontual no Brasil desde o Código Eleitoral, em seu art. 236, § $2^{\circ}$, que apresentava medida de apresentação imediata do preso ao juiz competente. Há também regulamentação pontual de um instuto de obrigatoriedade de audiência de apresentação nos artigos 180 e 184 do Estatuto da Criança e do Adolescente, bem como no Código de Processo Penal, que trazia a previsão da possibilidade da realização de uma audiência com o preso logo após a prisão no rito dos habeas corpus. (CARVALHO, 2017).

O marco legislativo para todas as prisões deu-se com o PIDCP, estando no ordenamento desde Decreto 592 de 6 de julho de 
1992 e com CADH, com vigência desde 6 de novembro do ano de 1992. Assim, tem-se como marco obrigacional a aceitação das normas convencionais instituídas no art. 9.3 do PIDCP e no art. 7.5 da CADH, nos quais é constituída a garantia de apresentação imediata do preso à autoridade judiciária.

Apenas em 2015 constitui-se o Projeto $\mathrm{Na}$ cional de Audiências de Custódia, promovido pelo Conselho Nacional de Justiça. A instituição deu-se de forma regular nos tribunais do país através do TCT 7, celebrado pelos membros do CNJ, Ministério da Justiça $(M J)$ e Instituto de Direito do Direito de Defesa (IDDD). O TCT 7 objetiva a implantação efetiva das audiências de custódia com vistas à apresentação do autuado à autoridade judiciária em no máximo 24 horas após a prisão em flagrante (CNJ, 2015). A partir desse momento, inicia-se a sua regulamentação em tribunais de todo o território nacional.

Dá-se especial destaque ao Tribunal de Justiça de São Paulo (TJSP) que, através do Provimento Conjunto n. 03/2015, regulou internamente a prática das audiências de custódia nos moldes atuais. Porém, sua repercussão aumenta a partir do julgamento da ADI 5.240, de relatoria do Ministro Luiz Fux que, em decisão de plenário do STF em agosto de 2015, declara a constitucionalidade da norma administrativa criada pelo TJSP (VILELA, 2016).

Um mês depois, ocorre o julgamento cautelar da ADPF 347, na qual o STF estabelece a obrigatoriedade da apresentação do preso à autoridade judiciária no prazo máximo de 24 horas, a partir do momento da prisão. Em dezembro do mesmo de 2015, o CNJ, através da R 213, disciplina a obrigatoriedade da audiência de custódia em caráter nacional.
Neste provimento há, ainda, a padronização dos procedimentos e a vinculação aos objetivos de afastamento da tortura, maus tratos e da garantia dos direitos fundamentais.

A R 213 prevê, logo no caput do artigo $1^{\circ}$, a necessidade de apresentação da pessoa presa em flagrante à autoridade judicial no prazo máximo de 24 horas do momento da prisão, o que não pode ser substituído pelo mero envio do auto de prisão em flagrante ao magistrado, devido à essencialidade da apresentação pessoal para a efetivação da audiência de custódia (CNJ, 2015).

Desta forma, ainda nos termos do artigo $1^{\circ}$ da R 213, há a obrigatoriedade do envio do auto de prisão em flagrante, bem como que deve ocorrer a presença pessoal do preso em audiência. Por outro, a mera comunicação do flagrante, nos termos do artigo 306, parágrafo único, do CPP, bem como a apresentação de decisão, não suprem a necessidade da realização da audiência de custódia. (AFLEN, 2017).

No que pese as audiências de custódia não serem restritas ao procediemnto flagrancial, cumpre esclarecer que o procedimento de flagrante foi o mais afetado pela modificação trazida pela R 213. Isto porque nas prisões pena, já havia o procedimento de realização de audiência obrigatória, denominada naqueles casos de audiências admonitórias. Portanto, a audiência de custódia vem como um modelo de controle de legalidade, sobretudo, das prisões cautelares, em especial do procedimento flagrancial.

A audiência de custódia é o momento da verificação dos requisitos de validade da prisão em flagrante e da necessidade de sua manutenção e, deve acontecer individualmente, mesmo que haja mais de um investigado pela prática do delito. Seu artigo 
$8^{\circ}$, VIII, prevê a impossibilidade do juiz fazer perguntas relativas aos fatos com o fim de produção de prova para a investigação ou para a ação penal (ROSA E BECKER, 2017) (CNJ, 2015).

O curto espaço de tempo entre a detenção e a audiência objetiva, além da celeridade, uma maior aproximação entre o preso e o magistrado que, sob a imediatidade dos acontecimentos, pode analisar com maior clareza e qualidade as informações referentes à autuação (ROSA E BECKER, 2017). Ademais, como o procedimento está pensado nas prisões cautelares, considera-se que neste prazo de 24 horas haja o tratamento de preso provisório, ou seja, se está diante de pessoa presumidamente inocente que não deve passar por maiores delongas aguardando a verificação da necessidade de sua manutenção na prisão.

Assim, este sistema com a imposição de prazos para a realização da custódia, no intuito de tornar o mais célere o possível a verificação da legalidade do ato prisional, bem como de evitar prisões desnecessárias é transportado de diversos outros países. 0 Reino Unido utiliza de um prazo de 24 horas, prorrogáveis por até 36 horas, já na França tem-se prazo de 24 horas prorrogáveis por até 48 horas, na Alemanha o prazo é de até 47 horas e 59 minutos contados do ato prisional. Já nos países da Suécia, África do Sul e Portugal, o prazo é de 48 horas, enquanto na Espanha e na Argentina este prazo é de 72 horas, de modo que os regramentos internacionais acabam por deixar a cargo do país a regulamentação considerando parâmetros similares. (NICOLITT, 2015).

A ausência de juiz na comarca até o término do prazo estipulado pela resolução não retira a obrigatoriedade da audiência de cus- tódia, que deverá ser realizada pelo substituto legal. É essencial, também, a presença no local dos representantes do Ministério Público e da Defensoria Pública, no caso da inexistência de advogado. Se, por sua vez, houver advogado constituído no momento da lavratura do auto do flagrante, sua notificação deve ser feita pelo Delegado de Polícia (CNJ, 2015).

Assim, consta que as audiências de custódia teriam formato constituído para romper as barreiras frias do contato entre o juiz e o preso, de modo a relevar as mazelas do processo penal, humanizando o procedimento. Outrossim, haveria a limitação das atuações da polícia que seriam de conhecimento público com relatos de abusos e ilegalidades que, pela demora natural do processo, acabariam se perdendo e não sendo apuradas (SILVA E FELIX, 2017).

Apesar de sua regulamentação ter ocorrido somente em 2015, a realização de audiências de custódia tem previsão normativa desde 1992, pelo art. 9, item 3 do PIDCP, e pelo art. $7^{\circ}$, item 5, da CADH. A omissão legislativa brasileira suscitou a iniciativa do CNJ de criar uma regulamento para a audiência de custódia em obediência aos pactos dos quais o Brasil é signatário (VILELA, 2016).

Tais tratados internacionais, que versam sobre direitos humanos e são ratificados pelo Estado brasileiro, tornam-se ferramentas de controle de criação de normas, ou seja, de controle de convencionalidade. Isso significa que a incorporação daqueles no direito pátrio autoriza os tribunais a compatibilizar a legislação nacional com o seu conteúdo (MAZZUOLI, 2011).

Os tratados internacionais de direitos humanos, quanto ao seu ingresso no ordenamento brasileiro, possuem quatro correntes 
doutrinárias de aceitabilidade da normatividade dos tratados e convencionais internacionais frente ao texto originário da CF: i) Os tratados internacionais teriam caráter supraconstitucional, deste modo seriam superiores à constituição em razão da força axiológica e por servir de princípio prévio ao texto escrito-constitucional; ii) Os tratados internacionais deveriam ter caráter constitucional, portanto, seriam equiparadas ao bloco de constitucionalidade; iii) deveriam os tratados ter caráter infraconstitucional, mas supralegal, isto é, seriam textos com normatividade superior ao de texto legal, mas inferior ao texto constitucional; e iv) estes tratados internacionais ingressariam no ordenamento em paridade com a legislação ordinária. (PIOVESAN, 2008).

A Emenda Constitucional 45 de 2004 (EC45) apresentou-se como referência para a reforma do Poder Judiciário e implicou na mudança do paradigma de percepção dos tratados internacionais no ordenamento brasileiro. Desta forma, consideram-se dois marcos para a percepção dos tratados internacionais no brasil, em especial para o pacto de San José da Costa Rica, norma que uma vez recepcionada permitiu a formulação das audiências de custódia, objeto deste trabalho.

Seguindo os parâmetros de países internacionais, foi introduzido pela EC45 o artigo $4^{\circ}$ da CF, que passou a estabelecer os princípios que determinam nas relações internacionais a prevalência dos direitos humanos. Assim, a mudança do paradigma constitucional implicou na positivação de regras mais claras quanto à validade e à aceitação das normas do direito internacional. Nesse contexto, tem-se que a EC45 formatou um modelo pelo qual o ordenamento externo, mediante um processo legislativo similar ao de emenda à constituição, assume o status constitucional. Portanto, ensejou o chamado bloco de constitucionalidade, de modo que trata-se como texto constitucional aquele originário, aquele derivado, bem como os tratados de direitos humanos que passem pelo modelo previsto na EC45 (GOMES; MAZZUOLI, 2009).

O ordenamento jurídico, por sua vez, possuía tratados anteriores à EC45. Portanto, seria necessária a compreensão do status jurídico destes tratados anteriores. Assim um marco de referência surge após discussões doutrinárias do julgamento do Recurso Extraordinário n. 466.343, de 3 de dezembro 2008. Neste recurso o STF pacificou o entendimento de que os tratados internacionais dos quais o Brasil era signatário em momento anterior a EC45 formatariam modalidade própria, entre a constitucionalidade e a legalidade, a partir do juízo de convencionalidade. Adotou-se a tese da supralegalidade, observando o pacto de San José da Costa Rica, de modo que o caso analisado deu-se decorrente da vedação da prisão do depositário infiel. Desta forma, compatibilizou o STF a legislação nacional com a CADH, ao interpretá-la em conjunto com o inciso LXVII do art. 5o. da CF. Portanto, a partir deste paradigma a CADH passou a tomar caráter supralegal, mesmo que sua vigência no ordenamento se desse desde o decreto 678 de 6 de novembro de 1992.

Deve-se esclarecer ainda que a experiência internacional não exclui a tese da supralegalidade, pelo contrário, indica a aceitabilidade desta em relação aos tratados internacionais de direitos humanos. Deste modo, são percebidos nos países signatários da CADH todas as 4 teorias sobre tratados internacionais em vigência. Tal contexto traz relevância, pois uma vez consideradas todas 
as teorias em validade, tem-se a consequência destas valerem também como critério hermenêutico de interpretação jurídica. (MAUÉS, 2013).

Nesse sentido, considerar que as audiências de custódia no ordenamento brasileiro são decorrência da $\mathrm{CADH}$, ou seja, de um tratado de direitos humanos com caráter supralegal, implica também que este arcabouço normativo serve de critério balizador de interpretação jurídica e de guia de aplicação para o instituto. Portanto, as audiências de custódia devem ser adequadas aos fins como combate à tortura, à garantia de direitos humanos e à percepção de vida digna a qualquer cidadão frente o Estado.

A R 213 traz, ainda, em seu preâmbulo a clara intenção de combater a tortura e demais abusos cometidos por autoridades policiais quando da prisão. Seu artigo 11 dispõe que a existência de indícios de tortura, bem como a sua declaração pelo detido, obrigam o juiz a registrar tais informações e tomar as providências cabíveis para a investigação da denúncia, com vistas à preservação da saúde e segurança da vítima.

Não é à toa que o parágrafo único do artigo $4^{\circ}$ da R 213 veda expressamente a presença dos agentes policiais responsáveis pela prisão ou investigação do delito na audiência de custódia (CNJ, 2015).

Em decorrência do caráter supralegal dos tratos e do controle de convencionalidade, fazia-se necessária a implementação da audiência de apresentação, como o fez o Projeto Audiência de Custódia. Tal necessidade representava não apenas a indicação do cumprimento legislativo, mas a exigência de humanização do processo de prisões cautelares, pelos quais a violência policial tornava-se despercebida pelo decurso do tempo, ao qual os papeis eram incapazes de registrar (MELO, 2016).

Além disso, as audiências de custódia revelam a aplicação dos artigos 306, 310, 311 e 312 do CPP. Nesse sentido, uma vez encaminhado ao juiz o auto de prisão em flagrante, deve haver a verificação da existência do binômio legalidade e necessidade da prisão, de modo a buscar uma eventual redução dos possíveis maus tratos e torturas, conferindo também o direito do preso de ser ouvido, o contraditório e a ampla defesa (LOPES JR. E PAIVA, 2014). Quanto ao procedimento, a audiência deve contar com a presença de um membro do Ministério Público e da Defensoria Pública, ou advogado particular, caso seja de interesse do réu.

Destaca-se que as audiências de custódia, para cumprir sua finalidade, não devem ser reduzidas a meros protocolos que têm de ser cumpridos, mas sim, faz-se necessária a apresentação das mazelas do processo penal. Portanto, para a audiência de custódia não pode servir de protocolo para blindar a tortura, dando ares de legalidade ao procedimento violento (WERMUTH, 2017).

Assim, as audiências de custódia são envoltas ainda num processo sistémico de tutelas contra a tortura e a atuação com violência desnecessária perpetrada no âmbito dos processos investigativos. Nesse sentido, o Instituto Conectas produziu relatório acerca da implementação deste procedimento, denominando "Tortura Blindada, como as instituições de justiça perpetuam a violência nas audiências de custódia". Este estudo indiciou o efetivo descaso no cumprimento do Projeto Nacional Audiência de custódia, bem como na ineficiência dos mecanismos de controle das próprias audiências. (CONECTAS, 2017). 
É nesse sentido que o presente trabalho busca a compreensão numérica das audiências de custódia no Estado do Ceará, para que, mediante os números, perceba-se a realidade vigente e a consequente compreensão da eficácia do sistema legal aplicado. Portanto, com análise perfunctória do procedimento, é possível entender se as audiências estariam sendo meros protocolos ou se estariam cumprindo seus objetivos.

\section{PARÂMETROS DE ANÁLISE DOS DADOS}

Este trabalho utiliza como parâmetros os dados de quantidade de autuações mês a mês no ano de 2016 e em seguida é feita a análise das espécies de decisões encontradas, sejam estas decisões relativas a decreto de prisão preventiva, concessão de liberdade provisória ou relaxamento de prisão por ilegalidade. Por fim, há um hiato entre os casos efetivamente julgados e aqueles que tiveram a audiência remarcada por qualquer motivo.

Com a colocação dos dados em formato de rol, seguiu-se o cálculo das medidas de tendência central, para que se estabelecessem parâmetros quantitativos de análise. Desta forma, utilizou-se a fórmula da média e analisou-se a quantidade de autuações e decisões tabuladas em sequência temporal.

Entretanto, ao perceber as distribuições do rol de dados analisados, notou-se que as margens dos dados teriam grande distância. Isso quer dizer, havia uma discrepância considerável entre o verificado no mês de mais autuações e o percebido no mês de menos autuações. Desta forma, foi necessária também a compreensão dos dados de dispersão.

As medidas de dispersão servem para compreender o quão homogêneo é um dado, através da consideração de dados aproximadamente simétricos. Desta forma, a medida de dispersão padrão utilizada em estatística é a variância, calculada a partir da seguinte fórmula, onde $\mathrm{s}^{2}$ = variância, xi é dado tabulado $\times\left(\_\right)$a média e $n$ a quantidade de dados (MORENTI, 2010):

Imagem1: fórmula de variância

$$
s^{2}=\frac{\sum_{i=1}^{n}\left(x_{i}-\bar{x}\right)^{2}}{n-1}=\frac{\sum_{i=1}^{n}\left(x_{i}^{2}\right)-n \bar{x}^{2}}{(n-1)} .
$$

(FONTE): Imagem formatada

Esta medida apresenta defeito de análise quanto à dimensionalidade. Isso porque a variância sempre constitui um dado com a dimensão originária ao quadrado. Por exemplo, nas análises que foram feitas sobre a quantidade de prisões, as variâncias são calculadas em quantidade de prisões ao quadrado. Com essa dimensionalidade, torna-se complexo e inviável a formulação de parâmetros de comparação.

Desta forma, surge a medida de dispersão do desvio-padrão, que permite a verificação da medida na mesma dimensão da análise originária. O desvio-padrão é calculado pela raiz quadrada da variância (MORENTI, 2010):

Imagem2: fórmula de desvio-padrão

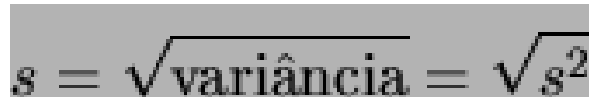

Fonte: Imagem formatada.

Em seguida, a outra medida utilizada para se concluir com maior precisão a dispersão de um dado é o denominado coeficiente relativo de Pearson. Este índice traz a probabilidade de um resultado dispersar da média, 
e é calculado com base na variância. Para isto, deve-se dividir o desvio-padrão pela média e multiplicar seu resultado por 100, para se ter o dado percentual e adimensional. Calcula-se, então, o coeficiente de Pearson pela seguinte fórmula, onde CV é o coeficiente de variação, s é o desvio-padrão e $x$ é a média.

Imagem3: fórmula de

Coeficiente de Pearson

$$
C v=100 \cdot \frac{s}{\bar{X}}
$$

Fonte: Imagem formatada.

Desta forma, é possível verificar a estabilidade das decisões, mediante a verificação quantitativa dos dados de tendência central e de dispersão dos dados, confrontando-os com a teoria para que possam constatar a real situação das audiências de custódia na comarca de Fortaleza no ano de 2016.

\section{VERIFICAÇÃO DE DADOS}

Na comarca da capital do Estado do Ceará, as audiências de custódia foram implementadas e iniciaram a sua efetivação após a edição da R14, do Órgão Especial do TJCE. A 17a Vara Criminal de Fortaleza passou então a concentrar a estrutura e os trabalhos relativos a todos os processos de custódia, de modo que tornou-se a Vara Única e Privativa de Audiências de custódia. Tal vara conta, em sua estrutura, com quatro juízes vinculados, quatro promotores e dois defensores titulares, auxiliados por mais dois defensores deslocados das demais varas criminais. Além, de nove servidores, seis estagiários, todos do TJCE, além de equipe com seis po- liciais militares e dois servidores da Secretaria de Justiça.

A estrutura da Vara Única de Audiências de Custódia de Fortaleza oscilou ao longo do ano de 2016 a depender da disponibilidade do Tribunal de Justiça, em decorrência do multirão ocorrido no período de 15 de fevereiro a 04 de março, chegou a contar com 07 (sete) juízes (três a mais que o efetivo da unidade), cada um em uma sala de audiência, sete defensores públicos e sete promotores, tendo como meta ouvir uma média de 70 presos por dia. Embora em momento posterior ao multirão tenha havido a estabilização de seu formato original. No multirão, ocorreram 669 audiências, sendo elas resultando em 391 prisões preventivas, 231 pessoas soltas com medidas cautelares e 47 alvarás de soltura. Além disso, a segurança interna e a escolta dos autuados foram reforçadas.

Ainda de acordo como regramento alencarino, as audiências só podem ocorrer após a coleta das informações prévias dos presos na Central Integrada de Apoio à Área Criminal (CIAAC), órgão que tem por função retirar as certidões de antecedentes criminais do custodiado e organizar a documentação, de modo a encaminhar para a vara e permitir a realização da audiência de apresentação.

Para fins deste trabalho e melhor organização, realizou-se um relatório de mapeamento das audiências de custódia, contendo: i) quantidade de autuados; ii) quantos autuados compareceram efetivamente às audiências; iii) se houve decretação de prisão preventiva ou concessão de medidas cautelares diversas da prisão, ou se houve relaxamento de prisão, tudo nos termos do art. 310 do Código de Processo Penal. 
Para fins metodológicos, este trabalho analisou tão somente os dados obtidos no período de janeiro de 2016 a dezembro de 2016, período no qual houve 7433 prisões em flagrante, das quais 5948 tiveram decisão de mérito. Nas demais, houve a remarcação por algum motivo externo, tal qual falta de documentação ou impossibilidade estrutural.

Desta feita, verificaram-se os dados de tendência central, de dispersão, no caso, o coeficiente relativo de Pearson, da variância e do desvio-padrão. Assim, a distribuição das quantidades de prisões nos meses ficou da seguinte forma:

Gráfico 1: quantidade de prisões

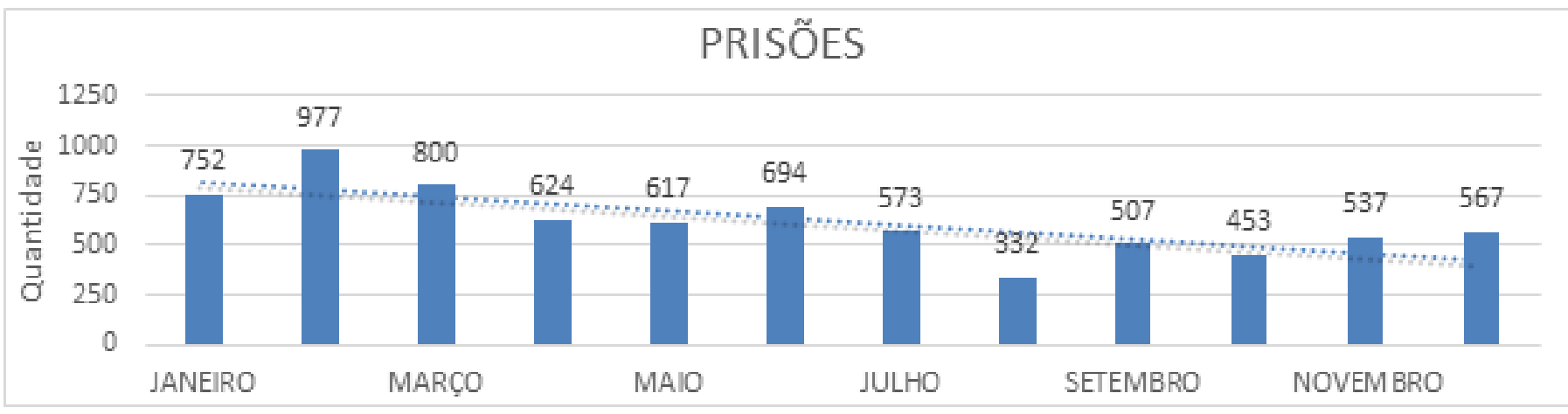

(FONTE: Relatório $17^{\mathrm{a}}$ vara).

Realizou-se uma média de 619,4166667 autuações por mês, com uma variância de 26523,24306 autuações². Observa-se uma linha de tendência descrente ao longo do ano, cuja angulação, muito embora, seja reduzida, de modo que os meses de final de ano tiveram sensivelmente menos audiências que aqueles do começo.

Há a verificação de um desvio-padrão de 170 prisões, fato que indica uma variação elevada nos dados do gráfico. Desta feita, no mês de fevereiro houve uma quantidade de prisões que representou quase o triplo das feitas em agosto. Tal fato demonstra inconstância no número de prisões no ano, o que indica haver considerável discrepância entre as prisões nos meses.

Diante do dado estritamente numérico, é capaz de ser inferido, portanto, que há me- ses em que as atividades foram intensificadas e outros em que as atividades foram represadas. Esta inferência é considerada coeteris paribus, sem se preocupar com a possibilidade de crimes sazonais, vez que estes não indicam atuação policial sazonal, isto é, o fato de existirem mais certos crimes em épocas específicas não implica diretamente em existirem mais ou menos prisões no período mencionado.

Nos meses de junho e julho não houve nenhuma audiência com apresentação dos presos. Tal fato deu-se após rebeliões ocorridas (em maio) nos presídios de Fortaleza, o que causou a suspensão das audiências e fez com que as decisões fossem tomadas mediante o antigo procedimento de apresentação de auto de prisão em flagrante. No que pese a R 213 ter previsão expressa que o fato de se proferir alguma decisão não exclui 
a necessidade da realização da custódia, não foi o que se observou nos procedimentos adotados no âmbito do TJCE. (SILVA NETO, 2016).

Desta feita, das 7433 autuações, apenas 5948 foram decididas conforme o procedimento, seja com a apresentação do preso ou não, de modo que todas as outras foram remarcações. Assim, houve 3491 decisões de prisão preventiva, 2426 decisões de liberdade provisória com ou sem prisão apenas 31 decisões relativas à relaxamentos de prisão, conforme gráfico abaixo:

Gráfico 2: decisões em audiência

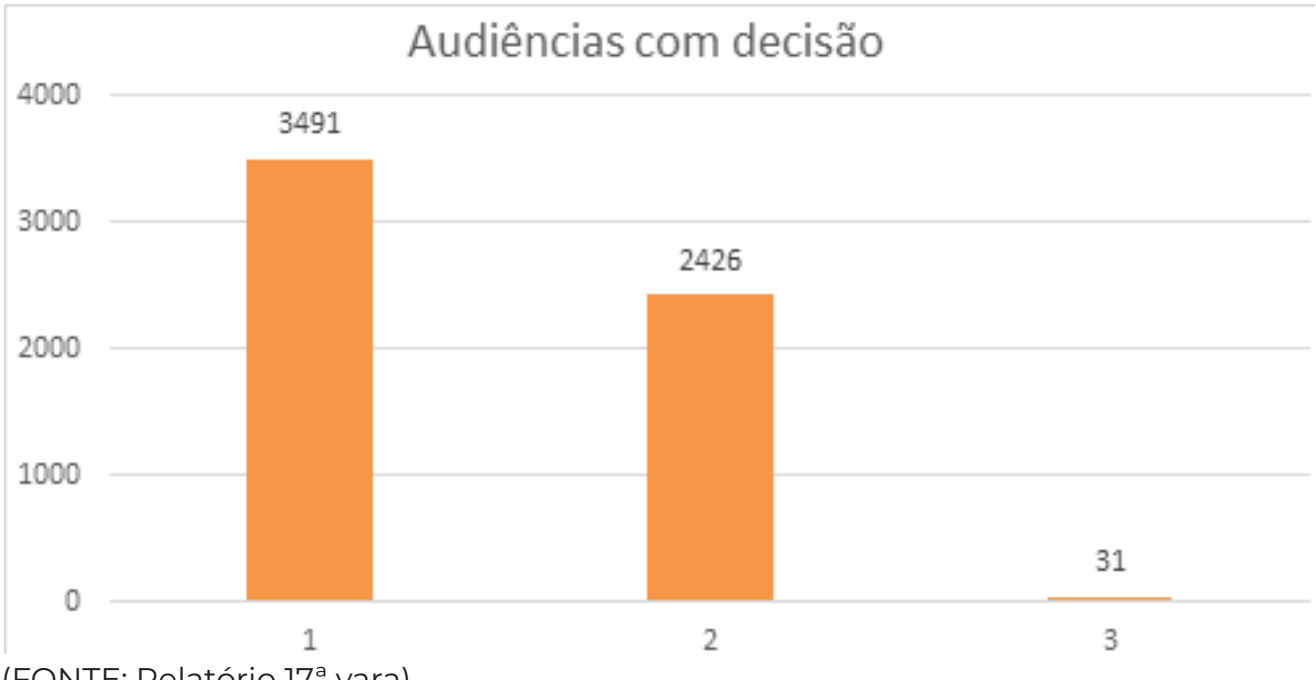

(FONTE: Relatório $17^{\mathrm{a}}$ vara)

Neste período houve uma média de 290,91 decisões por prisão preventiva, enquanto a média de decisões por liberdade provisória foi de 202,16 e a de relaxamentos foi de 2,58, tomando por base a distribuição mês a mês. Formulou-se, desta forma, o gráfico abaixo, onde 1 significa a média de prisões, 2 a média de liberdades provisórias e 3 a média de relaxamentos.

Gráfico 3: Médias mensais das decisões

\section{Médias de decisões}

375 ,

300 , 290,9167

225 ,

150 ,

75 ,

0 ,

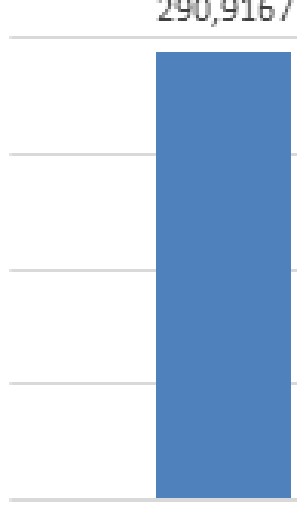

1

Fonte: relatório $17^{\mathrm{a}}$ vara

202,1667

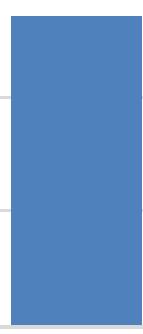

2
2,5833

3 
Em relação aos processos globais, em 52,25\% dos casos houve decretação de prisão preventiva, enquanto em 36,31\% houve concessão de liberdade provisória e apenas em 0,46\% houve relaxamento por ilegalidade. Nos demais casos, ou seja, em $11,51 \%$, sequer houve a audiência de custódia, tendo sido remarcada por motivo diverso, tal como falta de documentação, ou algum outro fator externo que ocasionasse a remarcação da audiência de custódia.

Gráfico 4: pizza decisões totais \%

\section{DECISÕES NAS CUSTÓDIAS}

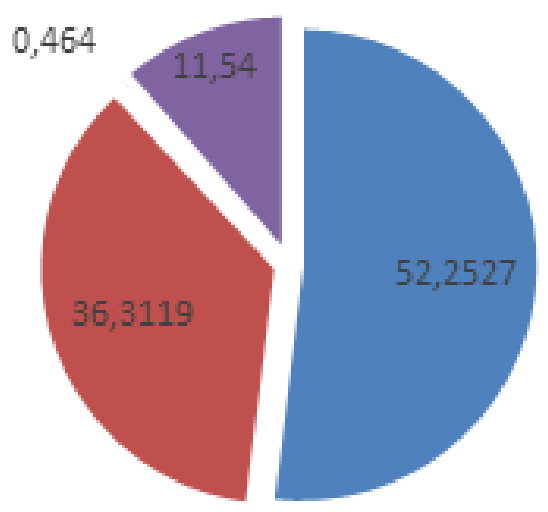

- 1 $-2$

$=3$ .4

FONTE: Relatório $17^{\mathrm{a}}$ vara

Tais dados mostram que há número significativo de decisões de prisão e liberdade provisória, bem como demonstram uma intensa quantidade de audiências remarcadas. As remarcações indicam um período de formulação e adaptação das estruturas, de modo que foi bastante comum que não foram raras as audiências que não se realizaram por questões estruturais ou mesmo por falta de organização administrativa e preparação prévia de servidores, instalações e protocolos de trabalho. Assim, tem-se que as audiências tiveram o procedimento adaptado ao longo do ano, em especial no momento posterior as rebeliões que paralisaram a realização dos procedimentos, para exigir que só fossem realizadas audiências após o envio de todos os documentos pela CIAAC. (SILVA NETO, 2016).

Cumpre destacar, ainda, que as decisões de relaxamento mostraram-se, do ponto de vista quantitativo, praticamente insignificantes perante o total de casos. Isto é, se há ilegalidade, esta não está efetivamente chegando ao conhecimento do poder judiciário, ou se está chegando, não vem sendo reconhecida.

Ocorre que a hipótese de não se chegar ao conhecimento do Poder Judiciário os relatos de maus tratos não se sustenta, vez que o próprio CNJ guarda dados de relatos, que indicam que em pelo menos 7\% das prisões são denunciadas agressões policiais. (CNJ, 2015). Ademais, o histórico brasileiro de violência policial implica em descredibilidade desta hipótese, voltando a crer numa violência estrutural que aceita a tortura e os maus tratos, fazendo das audiências de custódia um mero instrumento para dar ares de legalidade ao procedimento viciado. (WERMUTH, 2017).

Ademais, percebeu-se intensa discrepância com os dados dos coeficientes relativos de Pearson, unidade que serve para indicar o quanto uma amostra de dados apresenta dissidência de forma comparável com outras. Destarte, notou-se a partir da discrepância entre os dados que mostrou coeficiente relativo de Pearson superior a 106,2\%, quando analisado o dado relaxamento de 
prisão, ou seja, o dado é mais de 3 vezes mais disperso que o dado de decretação de prisões preventivas, que apresentaram apenas $28,16 \%$. Desta feita, há o indicativo de que as decisões relativas às prisões preventivas são mais estáveis do que aquelas em termos de relaxamento de prisão ou mesmo de concessão de liberdade provisória. A tabela abaixo segue com os coeficientes de dispersão de Pearson, onde os dados 1 representam total de autuações, 4 total de prisões preventivas, 7 total de decisões por liberdade provisória e 8 total de decisões por relaxamento por ilegalidade.

Gráfico 5: Coeficiente de pearson

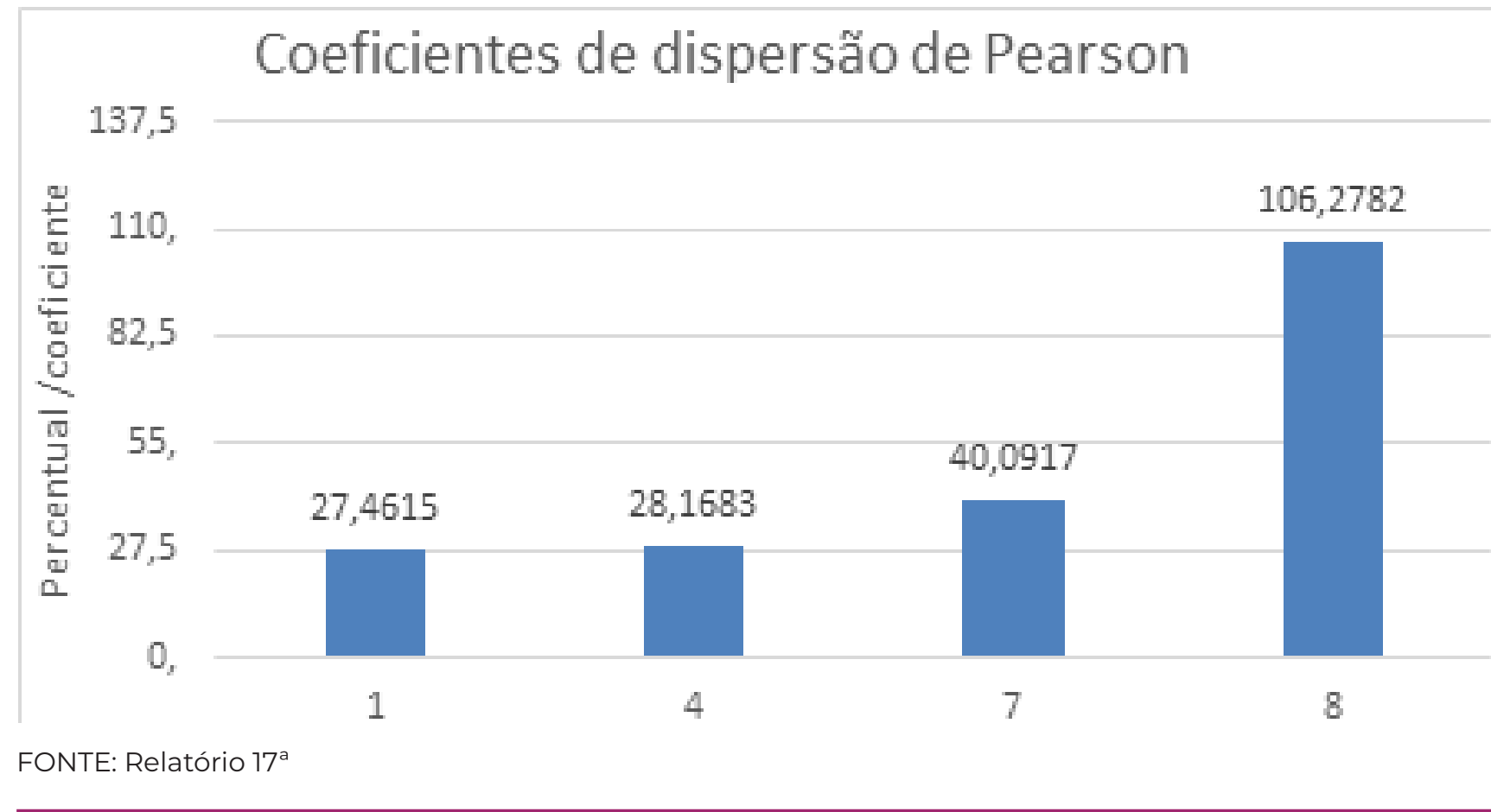

Chama atenção que, de acordo com os dados dos meses de janeiro, fevereiro e julho, não houve nenhum relaxamento de prisão. Desta feita, percebe-se a incidência baixa de relaxamentos de prisão que sugere ou uma polícia atuante próxima à perfeição, ou uma situação de audiências feitas de forma protocolar, que busca apenas o cumprimento da etapa processual, como sugerido por Wermuth (2017).

Cumpre trazer ainda que as ilegalidades as quais se imaginava combater não têm refletido em números nas custódias. Outrossim, há visão enraizada que estranhos ao sistema penal causariam entrave, de modo que pesquisadores, ou questionadores dos sis- temas de direitos humanos são tidos como figuras incômodas no ambiente prisional. (MELLO AT ALL, 2017).

Considerando ainda que é bastante improvável uma atuação policial próxima à perfeição, de modo que se assim o fosse sequer seriam necessárias às audiências mencionadas, há o indicativo numérico de uma subnotificação de casos de ilegalidade nas prisões. Ainda assim, as audiências de custódia buscam romper com o fetichismo da prisão como solução, mesmo que ainda não se perceba maior efetividade no mecanismo. (CARDOZO, 2017).

Ademais, o sistema jurídico de percepção 
das torturas ainda é insuficiente para reconhecer os relatos de torturas e maus tratos. Percebe-se uma falha estrutural nos mecanismos de verificação de tortura e na percepção dos atores jurídicos quanto à existência ou não de maus tratos no procedimento prisional (FORTES, 2014). Desta forma, as audiências de custódia, que deveriam ter insurgido como mecanismo de prevenção e meio para facilitar a tutela dos direitos humanos não têm, pelo menos no Estado do Ceará, no período de 2016, relevado como efetivo para tal objetivo (BRAGA, 2014).

O Instituto Conectas Direitos Humanos também seguiu na linha de verificação das falhas no combate à tortura e a violações de direitos humanos no âmbito das audiências de custódia. Assim, percebeu-se que há na cultura dos operadores do sistema a tendência de simplesmente omitir ou ocultar violações, de modo a transparecer nas linhas do papel um ar de legalidade. (CONECTAS, 2017). Por outro, o Poder Judiciário tem a necessidade de expandir essa prestação de contas com a sociedade, realmente verificando a existência ou não de torturas, de modo que a atuação no combate à tortura com respostas efetivas constitui passo de consolidação democrática. (JESUS, 2016).

Em relação às análises numéricas, deve-se ponderar ainda que as massas amostrais coletadas não permitem absoluta precisão de dados, mas servem de indicativo para aquilo que tem se tornado a aplicação das audiências de custódia no Estado do Ceará. Isso é, refletem tanto as falhas quanto os acertos no instituto, que pelo que foi verificado, ainda está em conformação para se chegar ao respeito aos paradigmas legalmente estabelecidos e uma efetiva garantia de proteção aos direitos humanos. De toda sorte, é possível verificar que há uma distân- cia entre a realidade observada nos dados e a expectativa de um procedimento de desencarceramento ou de reconhecimento de ilegalidades, como torturas e maus tratos.

Por fim, considera-se ainda nessa dispersão que a quantidade reduzida de dados traz maior imprecisão, não sendo razoável afirmar de maneira objetiva a motivação da efetiva discrepância entre estes dados, existindo meros indícios das causas. Daí, conclui-se que a implementação das audiências de custódia trouxe impacto no procedimento de análise das prisões em flagrante, mas que os dados de trabalho ainda não se estabilizaram para dar previsibilidade ao sistema.

\section{CONCLUSÃO}

As audiências de custódia configuram instituto de adequação das normas internas aos primados de direitos humanos dos quais o Brasil é signatário desde 1992. Entretanto, após anos alijando os cidadãos de um direito processualmente previsto, apenas em 2015 houve a efetivação do projeto nacional audiência de custódia.

Um projeto com esta envergadura implica em impactos na compreensão do processo penal e principalmente necessita de uma análise de efetividade para que as normas não se tornem letra morta, mas que venham a configurar a aplicação do direito como impositivo à sociedade. Nesse sentido, a ciência do direito observa não só o dever ser do direito, mas também como este tem ocorrido na prática e a sua efetividade.

Este trabalho teve por objetivo a análise da implementação das audiências de custódia na Comarca de Fortaleza, no Estado do Ceará, verificando os impactos da R14 do órgão especial do TJCE quanto à efetividade do 
instituto. Ainda assim, foi feita a verificação incidental com bases numéricas para que, a partir dos números, se possa ter uma noção mais segura dos efeitos destes normativos.

Nesta ocasião, analisou-se os dados de tendência central, no caso, médias dos dados de prisões e flagrante, liberdades provisórias e relaxamentos de prisão, bem como os dados de dispersão, especialmente o coeficiente relativo de Pearson. O período de análise foi o ano de 2016, com segregação e rotulação de dados mensalmente.

O total de autuações no ano foi de 7433 , das quais apenas 5948 tiveram uma decisão final. Esse dado indica que no período um número elevado de audiências, ou seja, 1485 foram adiadas por questões burocráticas. Tal fato sugere que, por ser um período de adaptação, os procedimentos ainda não estariam estabilizados. Portanto, a ausência de padrões e a falta de estrutura administrativa corroboram negativamente para a garantia da tutela dos direitos humanos e sobretudo para que sejam atingidos os objetivos da realização de uma audiência de apresentação.

Verificou-se que em 52,25\% das audiências a decisão foi de decretação de prisão preventiva, em $36,31 \%$ a decisão foi pela concessão de liberdade provisória e em apenas em $0,46 \%$ dos casos houve relaxamento por ilegalidade da prisão. Ademais, tem-se que os dados relativos às prisões preventivas demonstram maior estabilidade que os dados relativos aos relaxamentos de prisão ilegal e mesmo que as concessões de liberdade provisória. Com isso, há ainda o indicativo que os juízes estariam mais seguros ou mais propensos a decidir pelas prisões que pelas liberdades, bem como há a efetiva sugestão que os juízes não reconheçam ilegalidades mesmo que provalememte existentes e noticiadas.
Os dados relativos aos relaxamentos de prisão chamam atenção por sugerir discrepância extremamente elevada e quantidade reduzida de casos. Isso sugere uma subnotificação de casos de ilegalidade, de modo que as audiências de custódia em Fortaleza podem não estar conseguindo atingir seu objetivo de combater as torturas e maus tratos, ou de controlar a atividade policial. Portanto, na realidade, se estaria em plano extremamente distante da teoria a realidade, notadamente porque o respeito aos direitos humanos não parece ser o plano diretor das decisões judiciais, em desconformidade com os parâmetros legislativos.

\section{REFERÊNCIAS}

Aflen, Pablo Rodrigo. Resolução 213. (2017). Artigo $1^{\circ}$. In: (ORGs). ANDRADE, Mauro Fonaseca; Aflen, Pablo Rodrigo. Audiência de custódia: comentários à resolução 213 do Conselho Nacional de Justiça. São Paulo: Editora do advogado.

Braga, Ana Gabriela Mendes. (2014). Criminologia e Prisão: caminhos e desafios da pesquisa empírica no campo prisional. Revista de Estudos Empíricos em Direito, 1(1), 46-62. Disponível em: <http://www.reedpesquisa.org/ojs-2.4.3/index.php/reed/issue/viewlssue/1/1>. Acesso em: 05 fev. 2018

Brasil. Decreto 592 de 6 de julho de 1992. (1992). Atos Internacionais. Pacto Internacional sobre Direitos Civis e Políticos. Promulgação.

Decreto 678 de 6 de novembro de 1992. (1992). Promulga a Convenção Americana sobre Direitos Humanos (Pacto de São José da Costa Rica), de 22 de novembro de 1969.

Cardozo, Carlos Henrique. Reflexos sociais da audiência de custódia na cidade de Maringá (2017). Revista de ciências policiais da APMG. São José dos Pinhais, v. 1, n. 1, p. 56-77. Disponível em < http://www.pmpr.pr. gov.br/arquivos/File/APMG/04_Reflexos_sociais_da_ audiencia_de_custodia_na_cidade_de_Maringa.pdf> Acesso em 10 mar. 2018

Carvalho, Cláudia Bonard de. Audiência de custódia: avanços e desafios. (2017). Qual é o papel a ser exerci- 
do pela defensoria pública? (ORGs). Santoro, Antônio Eduardo Ramires; Gonçalves, Carlos Eduardo. Audiência de Custódia. Rio de Janeiro: d'plácido.

Concetas Direitos Humanos. (2017). Relatório Completo Tortura Blindada, Como as instituições do sistema de Justiça perpetuam a violência nas audiências de custódia. Conectas Direitos Humanos, p. 14. Disponível em: < http://www.conectas.org/pt/acoes/justica/noticia/47090-pesquisa-inedita- tortura-blindada> Acesso em 9 de julho de 2017.

Conselho Nacional de Justiça. (2015). Resolução n²13, de 15 de dezembro de 2015. Brasília.

(2015). Termo de Cooperação Técnica $n^{\circ}$ 7/2015. Disponível em: <http://www.cnj.jus.br/files/ conteudo/arquivo/2016/03/7525f63d46d1147032a1003f1c9271c9.pdf>. Acesso em: 4 de outubro de 2017.

(2015). Resolução $n^{\circ}$ 213/2015. Disponível em: <http://www.cnj.jus.br/files/atos_administrativos/ resoluo-n213-15-12-2015-presidncia.pdf>. Acesso em: 4 de outubro de 2017.

Fortes, Pedro Rubim Borges. (2014). Direitos e Restos humanos: uma hipótese ao enfrentamento jurídico -penal da tortura no Brasil. Revista de Estudos Empíricos em Direito, 1(1). Online. Disponível em: < http:// www.reed pesquisa.org/ojs-2.4.3/index.php/reed/article/view/7/7 > Acesso em: 07 nov. 2017.

Gerhardt, Tatiana Engel; Silveira, Denise Tolfo. (2009). Métodos de pesquisa. Porto Alegre: Editora da UFRGS Disponível em: <http://www.ufrgs.br/cursopgdr/downloadsSerie/derad005.pdf> acesso em 28 ago. 2017.

Gomes, Luiz Flávio; Manzzuoli, Valério de Oliveira. (2009) Tratados internacionais: Valor legal, supralegal, constitucional ou supraconstitucional. Revista de direito. Vol. XII, n 15. On-line. Disponível em: <http:// pgsskroton.com.br/seer/index.php/rdire/article/ view/1987/1890 > acesso em: 02 jan. 2017.

Jesus, Maria G. M. De; Gomes, Mayara de S.; Magnani, Nathércia C. M.; Ramos, Paula R.; Calderoni, Viviane. (2016). Jurisprudência do crime de tortura nos tribunais de justiça do brasil (2005-2010). Revista de Estudos Empíricos em Direito. Brazilian Journal of Empirical Legal Studies vol. 3, n. 1, jan 2016, p. 79-97. Disponível em: < http://reedpesquisa.org/ojs-2.4.3/index.php/reed/article/view/97/95 > Acesso em: 27 mar. 2018.

Lopes Jr., Aury; Paiva, Caio. (2014). Audiência de custódia e a imediata apresentação do preso ao juiz: rumo à evolução civilizatória do processo penal. Revista Liberdades do Instituto Brasileiro de Ciências Criminais, 77.
Maués, Antônio Moreira. (2013). Supralegalidade dos tratados internacionais de direitos humanos e interpretação constitucional. SUR - Revista Internacional de direitos humanos. vl. 218. 215-235.. On-line. Disponível em: < http://www.corteidh.or.cr/tablas/r32493.pdf > Acesso em 02 jan. 2018.

Mazzuoli, Valério de Oliveira. (2011). O controle jurisdicional da convencionalidade das leis. São Paulo: Editora Revista dos Tribunais.

Melo, Raphael. (2016). Audiência de Custódia no Processo Penal conforme a resolução 213 do CNJ e Projeto de Lei $n^{\circ}$ 554/2017 do Senado. Belo Horizonte: d' Plácido.

Mello, Priscila Vargas; Silva, Joana Coelho; Rudnick, Dani; Costa, Ana Paula Mota. (2017). Pesquisa empírica no Sistema prisional, constituindo experiências. Revista de Estudos Empíricos em Direito, 4(3). Online. Disponível em: < http://www.reedpesquisa.org/ojs-2.4.3/ index.php/reed/article/view/273/pdf_19 > Acesso em: 07 nov. 2017.

Morenttin, Luiz Gonzaga. (2010). Estatística Básica: Probabilidade e Interferência. Volume único. São Paulo: Pearson Pretice Hall.

Nicolitt, André. (2015). Processo Penal Cautelar: prisão e demais medidas cautelares. 2. ed revista, atualizada e ampliada. São Paulo: Revista dos Tribunais.

Piovesan, Flávia. (2009). Temas de Diretos Humanos. Cap. 1. 3. Ed. São Paulo: Saraiva.

Rosa, Alexandre Morais da; Becker, Fernanda E. Nöthen. (2017). O desafio de implementar a audiência de custódia: a decisão como ela é. Audiência de custódia, 11-28. Belo Horizonte: Editora D’Plácido.

Silva, João Ricardo Anastácio; Felix, Leonardo Martins. (2016). A Audiência de Custódia como Controle Jurisdicional da Prisão em Flagrante. Revista Eletrônica de Direito. 1(1). On-line. Disponível em: < http://www.unifil. br/portal/images/pdf/documentos/revistas/revista-juridica/edicao-2016.pdf >

Silva Neto, Aldemar Monteiro da. Audiência De Custódia Como Instrumento Humanitário Do Processo Pena (2016). 112 f. Dissertação (Mestrado em Direito) - Universidade de Fortaleza, Fortaleza.

Supremo Tribunal Federal. (2015). Ação Direta de Inconstitucionalidade $n^{\circ}$ 5.240/2015. Rel. Ministro Luiz Fux. Julgado em 20 de agosto de 2015. Disponível em: <http://redir.stf.jus.br/paginadorpub/paginador.jsp?docTP=TP\&docID=10167333>. Acesso em: 4 de outubro de 2017. 
(2015). Ação de Descumprimento de Preceito Fundamental n 347/2015. Rel. Ministro Marco Aurélio. Julgado em 9 de setembro de 2015. Disponível em: <http://redir.stf.jus.br/paginadorpub/paginador.jsp?docTP=TP\&docID=10300665>. Acesso em: 4 de outubro de 2017.

Tribunal de Justiça de São Paulo. (2015). Provimento Conjunto $n^{\circ}$ 03/2015. Disponível em: <https://api. tjsp.jus.br/Handlers/Handler/FileFetch.ashx?codigo=65062 $>$. Acesso em: 4 de outubro de 2017.

Tribunal de Justiça do Estado do Ceará. (2015). Resolução $n^{\circ}$ 14, de 05 de agosto de 2015. Fortaleza.

Wermuth, Maiquel Ângelo Dezordi. (2017). Audiências de custódia e proteção/efetivação de direitos humanos no Brasil. Revista Direitos Sociais e Políticas Públicas (UNIFAFIBE), 5(1). Online. Disponível em: <http:// www.unifafibe.com.br/revista/index.php/direitos-sociais-politicas-pub/article/viewFile/201/pdf > Acesso em: 18 jul. 2017.

Vilela, Hugo Otávio Tavares. (2016). Audiência de custódia - a inconstitucionalidade dos acórdãos da ADIN 5.240, da ADPF 347 MC/DF e da Resolução CNJ 2013 de 15 de dezembro de 2015. Revista dos Tribunais, 970, $195-208$

Data de submissão: 10/05/2018

Data de aceite: 26/04/2019 